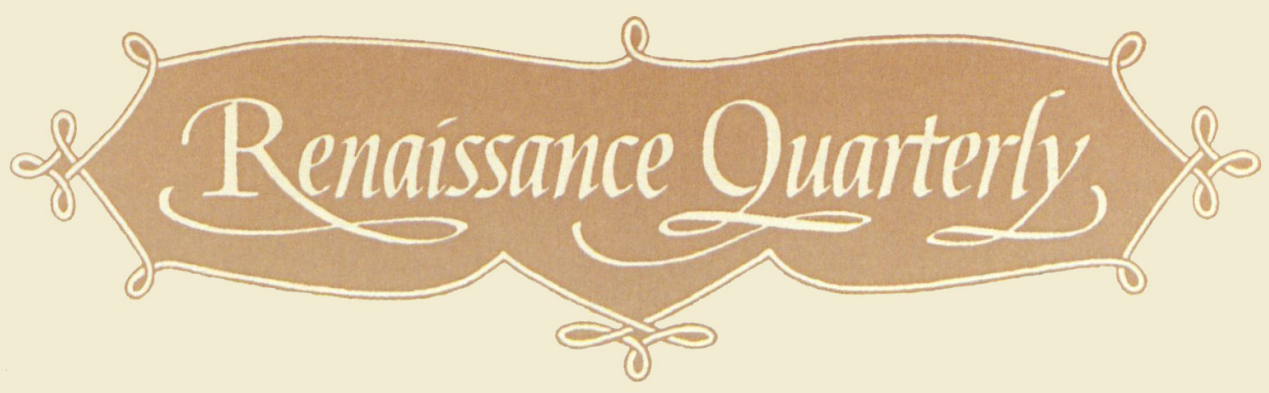

VOLUME LXVII • NUMBER 1 • SPRING 2014

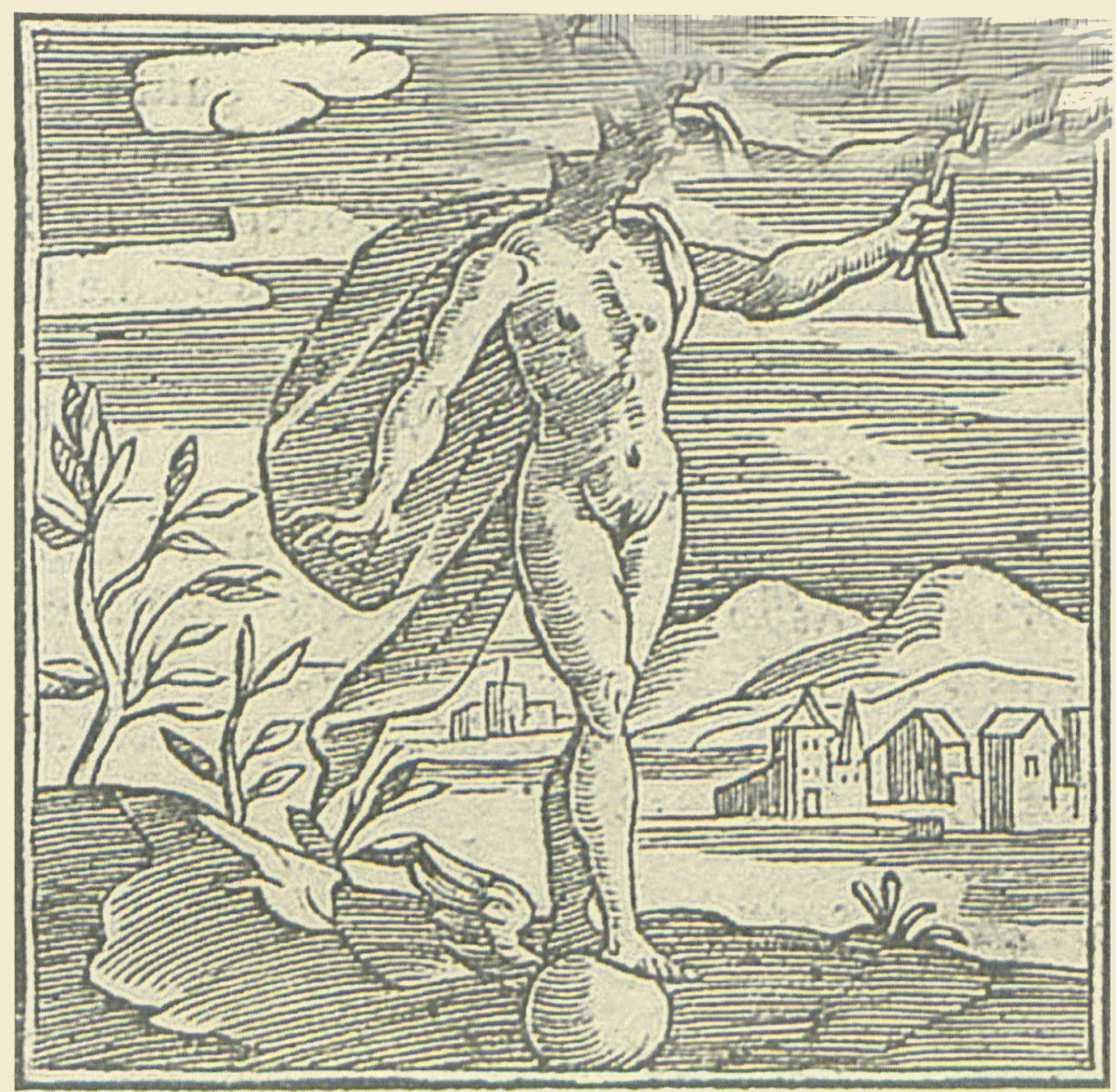

\title{
THE RENAISSANCE SOCIETY OF AMERICA
}

